\title{
Metastatic Adenocarcinoma Cerebrum Mimicking Tuberculoma in Pregnancy: A Case Report with Review of literature
}

\author{
Rahul Awasthi $^{1}$ Nilesh Jain ${ }^{1}$ Shrikant Rege ${ }^{1}$ Raghwan lyengar ${ }^{1}$ Abhishek Songara ${ }^{1}$ \\ ${ }^{1}$ Department of Neurosurgery, Sri Aurobindo Medical College and \\ Address for correspondence Rahul Awasthi, MCh, Department of \\ PG Institute, Indore, Madhya Pradesh, India \\ Neurosciences, Medanta Hospital, Indore, Madhya Pradesh 453111, \\ Indian J Neurosurg 2017;6:216-219. \\ India (e-mail: dr.awasthir@gmail.com).
}
Abstract
Keywords
- pregnancy
- adenocarcinoma
- metastasis

Brain tumors in pregnancy are rare phenomenon with variable outcomes. We present a case of adenocarcinoma cerebrum originated from the lung in a 24-year-old primigravida woman. The patient was operated successfully, and 6-month postoperative period was uneventful. A female child was born with cesarean section at full term.

\section{Introduction}

Adenocarcinoma is a neoplasm of epithelial tissue that has glandular origin. Adenocarcinoma of the lung is prone to give metastases to the liver, spleen, and brain. ${ }^{1}$ Brain metastasis is the most common intracranial tumor and has been observed in 10 to $40 \%$ of all cancer patients. ${ }^{2}$

Malignant tumors of the central nervous system (CNS) in pregnancy are rare and mostly diagnosed in the second trimester of pregnancy. ${ }^{3}$ Pregnant women presented with intracranial pathology rarely encountered in clinical practice that requires neurosurgical intervention. Brain tumor during pregnancy occurs very rare with an estimated incidence of 15 per $100,000 .{ }^{4}$ Generally pregnancy is not considered to be a risk factor for developing a brain tumor, and there is no evidence that shows higher prevalence of brain tumor in pregnant women as compared with nonpregnant women of the same age group. ${ }^{5}$ Physiologic changes during pregnancy, such as peritumoral edema as the result of fluid shift mostly in the second and third trimesters, occur in immunologic and hormonal status, and increased intra-abdominal pressure and hypercoagulability may have an adverse impact on neurologic outcome and exacerbate tumor-related symptoms. ${ }^{6}$

We present a case of primigravida at 30 weeks of pregnancy diagnosed as metastatic adenocarcinoma cerebrum, which radiologically mimics intracranial tuberculoma with its primary focus on originating from the lungs.

\section{Case Report}

A 24-year-old-woman presented with history of two episodes of convulsions with $7 \frac{1}{2}-$-month amenorrhea. The convulsions were generalized tonic and clonic in nature. The patient also had a history of headache, intermittent vomiting, and difficulty in speech from last 7 days. There was right-sided progressive weakness noticed since last 2 days. The patient had no history of any trauma or head injury in the recent past. She was antenatally registered and had no major obstetric complaints. She had no significant history. On examination she was conscious but drowsy. Her Glasgow coma scale (GCS) was E3V4M6. Bilateral pupils were normal in size and normal reacting to light. Rightsided hemiparesis with a motor power of $3 / 5$ presented in both upper and lower limbs. On preanesthetic assessment, the patient had a decreased air entry on left side of the chest without clinically appreciable adventitious sounds. She was clinically afebrile, and all other laboratory investigations including chest X-ray were within normal limits. Other systemic examination did not revealed any abnormality. Magnetic resonance imaging (MRI) of the brain showing a well-defined lobulated, centrally necrotic received

April 7, 2015

accepted

January 23, 2017

published online

April 21, 2017
DOI https://doi.org/

10.1055/s-0037-1601356. ISSN 2277-954X.
(C) 2017 Neurological Surgeons' Society of India
License terms

()(1) $\Theta \circledast$ 


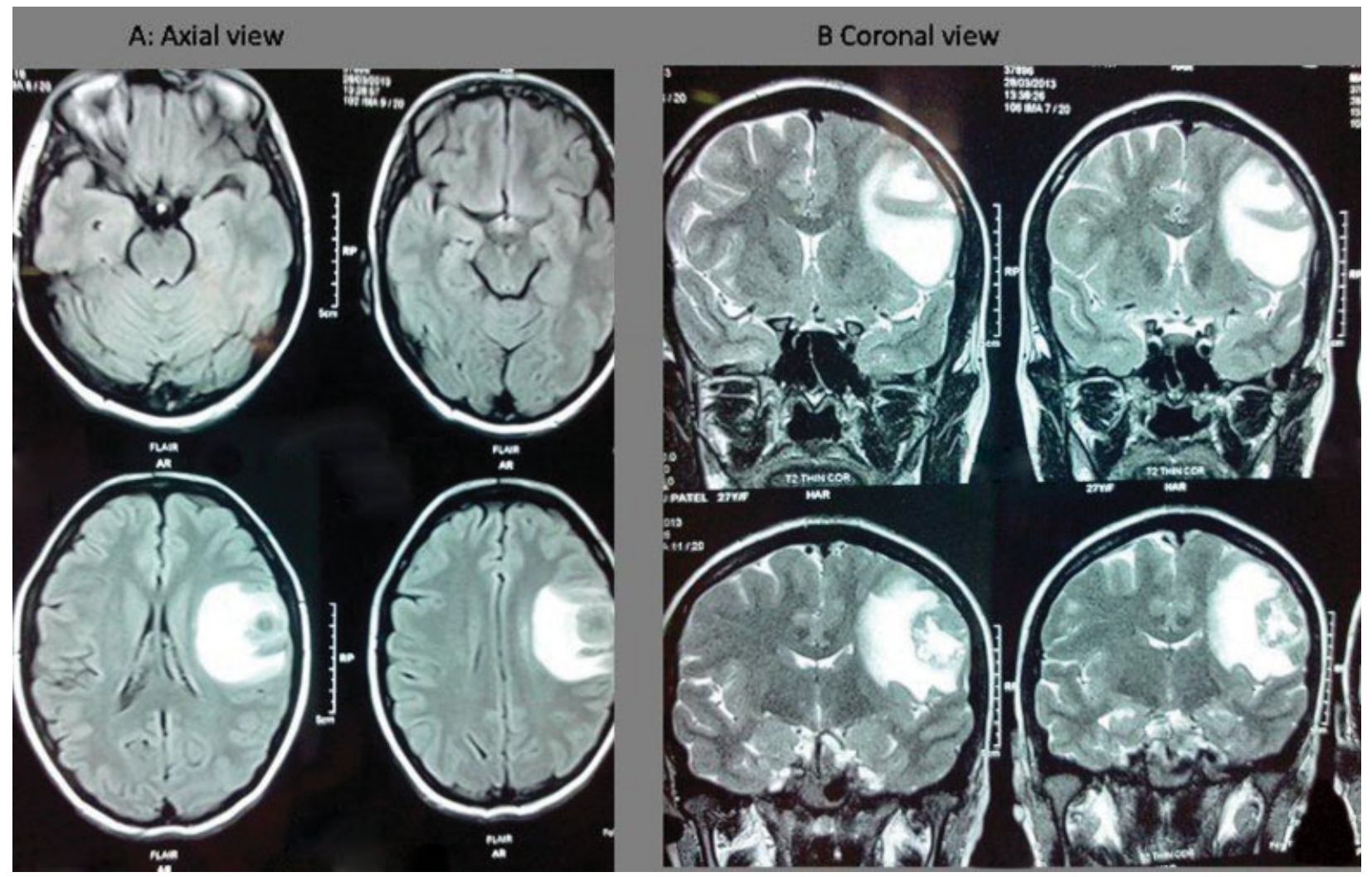

Fig. 1 Axial (A) and coronal (B) views of magnetic resonance image (MRI) of the brain demonstrating left posterior-frontal tumor with central necrosis.

space-occupying lesion (SOL) in the left posterior frontal suprasylvian region (-Fig. 1). Magnetic resonance spectroscopy (MRS) reveals significant elevated lipid lactate peaks with normal choline/creatine and choline/ $\mathrm{N}$ acetylaspartate (NAA) ratio. The overall imaging findings were suggestive of infective pathology, most likely tuberculoma. After a multidisciplinary consultation with the team involved, it was decided not to delay the surgery in view of rapid deterioration in patient's neurologic state and correlating radiologic findings. Anesthetic management was tailored for both pregnancy and an intracranial SOL. Fetal heart rate (FHR) was monitored prior to surgery and throughout the procedure and periodically for 24 hours postoperatively. An obstetrician was requested to remain as standby for FHR assessment and for an urgent cesarean section if required in case of fetal distress. The patient underwent a left frontoparietal craniotomy and gross total excision of tumor under general anesthesia. Intraoperatively tumor was soft, friable, and minimally vascular in nature. Subsequent obstetric and ultrasound checkups were normal. Histopathologic examination of resected specimen revealed features of metastatic adenocarcinoma-cerebrum (-Fig. 2). To look for primary cause, bronchial biopsy was done, which was suggestive of invasive, well-differentiated adenocarcinoma grade I (-Fig. 3). The patient was then advised for adjuvant chemoradiotherapy. The rest of her pregnancy was uneventful. She subsequently delivered a full-term healthy

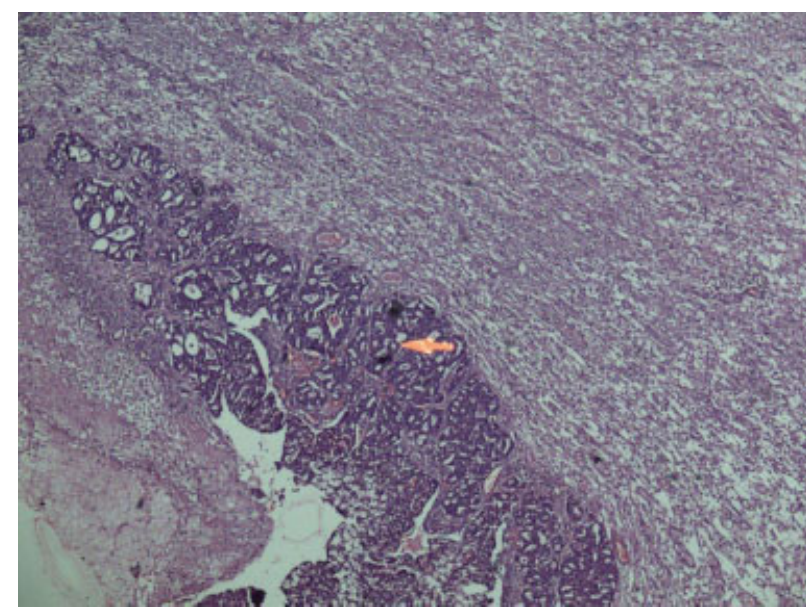

Fig. 2 H\&E section showing cerebral tissue with tumor mass composed of mild to moderate pleomorphic cells arranged in glandular pattern with intracellular mucin, tumor cell invading brain parenchyma with glial reaction.

baby through elective cesarean under general anesthesia. Six-month follow-up after discharge was uneventful.

\section{Discussion}

Tuberculoma accounts for 20 to $30 \%$ of all intracranial tumors in India. ${ }^{7}$ Its presenting features are as in decreasing order: seizers $(60-80 \%)$, headache and vomiting $(50-70 \%)$, 


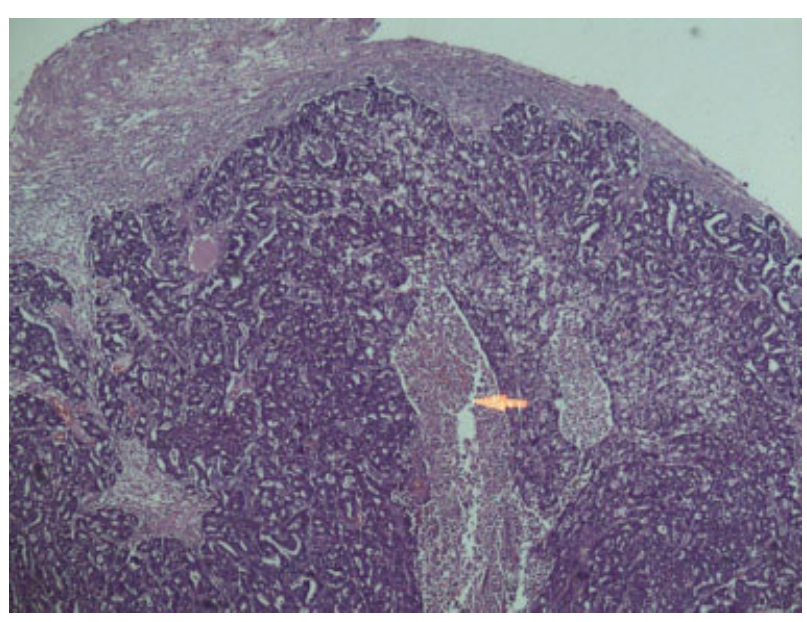

Fig. $3 \mathrm{H} \& \mathrm{E}$ section showing lung tissue having features of invasive, well-differentiated adenocarcinoma grade I.

and focal neurological deficits (33-68\%). They are usually present as solitary lesion, but 15 to $35 \%$ are multiple. They are mostly located in the frontal and parietal lobes and involve corticomedullary junction and periventricular regions. Vascular distribution of the lesion is more in middle cerebral artery (MCA) region. The computed tomography (CT)/MRI diagnosis of tuberculoma is nonspecific, and they have to be differentiated from other causes of SOLs such as metastasis, cysticercus granuloma, toxoplasmosis, fungal granuloma, and glioma. Primary brain tumors are likely to be mistaken for tuberculoma, which are more likely to calcify and produce a hyperdense lesion demonstrable on plain CT scan. ${ }^{8,9}$ MRI finding changes according to the stage of the lesion, that is, noncaseating granulomas and caseating granulomatous lesions with a solid center, and caseation in the center then usually liquefies. When tuberculoma presented with the elements of both liquefactive and coagulative necrosis showing mixed intensity on T1WI and T2WI with a rim of variable thickness, it mimics like a malignant tumor. ${ }^{9}$ MRS of tuberculomas is characterized by a prominent decrease in NAA/Cr and slight decrease in NAA/Cho. Lipid-lactate peaks are elevated in only $86 \%$ cases of tuberculomas. ${ }^{10} \mathrm{~A}$ similar pattern may also be observed in patients with toxoplasmosis and primary CNS lymphoma. CT/MRI of the brain is the usual initial investigation done when a intracranial mass is suspected. However, the diagnosis may be complicated by ambiguous radiologic findings; thus the tissue biopsy remains the gold standard. ${ }^{11}$

Brain tumors in pregnancy are very rare with an estimated incidence of 15 per 100,000 pregnancies. ${ }^{4}$ Haas et al proposed that the rates of intracranial tumor for women of childbearing age (15-44 years) was less than expected compared with that in the general population with an observed to expected ratio of $0.38 .^{12}$ For brain metastasis, the most common primary sites include the lung $(52.3 \%)$, followed by breast $(8.9 \%)$, renal $(5.4 \%)$, rectum (5.2\%), gastric (5.2\%), and colon (4.1\%). ${ }^{13}$ According to different series, at initial presentation up to $63 \%$ of the patients have multiple tumors, whereas 37 to $50 \%$ present with a single brain metastasis. ${ }^{14,15}$ Brain metastasis usually occurs at the gray-white junction and in the watershed areas of the brain at the same sites as cerebral emboli. The usual distribution is $\sim 80 \%$ cerebral hemisphere, $15 \%$ cerebellum, and $3 \%$ brainstem, similar to blood flow. ${ }^{2} \mathrm{~A}$ robust understanding of metastatic pattern from primary tumor is of interest for clinical use. Hess et al proposed that the single organ was the dominant source of metastases in seven sites, axillary lymph node from the breast (97\%), intestinal lymph node from the colon (84\%), thoracic lymph node from the lung (66\%), brain from the lung (64\%), meditational lymph node from the lung (62\%), supraclavicular lymph node from the breast (51\%), and adrenal gland from the lung (51\%). ${ }^{14}$

Lung cancer is one of the leading causes of death in women and has overtaken breast cancer. There are only a few cases in the literature describing the diagnosis of lung cancer during the course of a pregnancy. A very few cases have been reported in the literature; $77 \%$ were non-small cell carcinoma (NSCLC) and most of them were adenocarcinoma. Mostly patients were diagnosed with advanced disease not amenable to cure and requiring systemic treatment. The median diagnosis onset age reported is around 34 to 36 years, with a median gestational age at diagnosis of 27 to 29 weeks. Although the clinical profile of lung cancer is similar in pregnant and nonpregnant patients, a pregnant woman is more likely to be diagnosed with more advanced or metastatic disease. NSCLC in women is the most frequent lung cancer diagnosed and adenocarcinoma is the predominant histologic subtype. Postpartum maternal median survival is very poor and most patients die within 1 year after delivery. ${ }^{16-19}$

All risks and benefits associated with pregnancy, the different treatment modalities, the natural history of the disease, and outcomes must be discussed with the patient and their family members. Risk factors that have to be considered when deciding the most appropriate management include the severity and rate of progression of symptoms, gestational age and location and size of the tumor. Pharmacologic interventions include as, corticosteroids to reduce intracranial edema and accelerate fetal lung maturity and antiepileptics to control maternal seizures. Delivery should be preferably by cesarean section under general anesthesia to reduce the risks of cerebral herniation and placement of an epidural catheter. ${ }^{20}$

Anna et al suggested that neurosurgical procedures were performed during pregnancy in $48 \%$ and $19 \%$, respectively, in malignant and benign brain tumors. Adverse outcomes were not significantly associated with neurosurgical procedure, although these patients experienced significantly more cesarean deliveries, likely as part of a definitive treatment plan. ${ }^{5}$ Cohen-Gadol et al published an institutional series including 14 patients with intracranial neoplasms, 9 of whom underwent a neurosurgical procedure while pregnant. No fetal or maternal complications were directly related to these procedures, 
and all mothers who underwent surgery at or near term subsequently delivered healthy infants. ${ }^{21}$

\section{Conclusion}

Though MRI features can be suggestive of infective pathology and it may be compelling to start ATT empirically (esp. during pregnancy when there is a risk in intervention), a tissue diagnosis is necessary as uncommon lesions like a metastasis can be present.

\section{Conflict of Interest}

None.

\section{References}

1 Foco F, Dizdarevic-Spago D, Efendic R, Dizdarevic D, Babajic E, Sarajlic L. Adenocarcinoma metastaticum of the frontal region. Med Arh 2011;65(01):61-62

2 Biroli A, Cecchi PC, Pragal S, Hanspeter E, Schwarz A. Cerebral metastasis from a previously undiagnosed appendiceal adenocarcinoma. Case Rep Oncol Med 2012;2012:192807

3 Pantović S, Sparić R, Mijalčić R. [Metastatic brain tumour in pregnancy: a case report] [in Serbian]. Srp Arh Celok Lek 2012; 140(5-6):365-370

4 Lew PS, Tan WC, Tan WK, Tan HK. Dilemmas in management of brain tumours in pregnancy. Ann Acad Med Singapore 2010; 39(01):64-65

5 Terry AR, Barker FG II, Leffert L, Bateman BT, Souter I, Plotkin SR. Outcomes of hospitalization in pregnant women with CNS neoplasms: a population-based study. Neuro-oncol 2012; 14(06):768-776

6 Isla A, Alvarez F, Gonzalez A, García-Grande A, Perez-Alvarez M, García-Blazquez M. Brain tumor and pregnancy. Obstet Gynecol 1997;89(01):19-23

7 Ramamurthi B, Varadarajan MG. Diagnosis of tuberculomas of the brain. Clinical and radiological correlation. J Neurosurg 1961; $18: 1-7$
8 Ahmadi SA, Roozbeh H, Abbasi A, Bahadori M, Moghaddam KG, Ketabchi SE. Cerebral tuberculoma in pregnancy: overview of the literature and report of a case. Acta Med Iran 2011;49(01): 64-69

9 Hua Y, Tong H, Jin-Huan W. Cerebral tuberculoma located in left frontal lobe. Chin Med J (Engl) 2013;126:3

10 Khanna PC, Godinho S, Patkar DP, Pungavkar SA, Lawande MA. MR spectroscopy-aided differentiation: "giant" extra-axial tuberculoma masquerading as meningioma. AJNR Am J Neuroradiol 2006;27(07):1438-1440

11 Saini KS, Patel AL, Shaikh WA, Magar LN, Pungaonkar SA. Magnetic resonance spectroscopy in pituitary tuberculoma. Singapore Med J 2007;48(08):783-786

12 Haas JF, Jänisch W, Staneczek W. Newly diagnosed primary intracranial neoplasms in pregnant women: a population-based assessment. J Neurol Neurosurg Psychiatry 1986;49(08): 874-880

13 Narita Y, Shibui S. Strategy of surgery and radiation therapy for brain metastases. Int J Clin Oncol 2009;14(04):275-280

14 Hess KR, Varadhachary GR, Taylor SH, et al. Metastatic patterns in adenocarcinoma. Cancer 2006;106(07):1624-1633

15 Neves I, Mota PC, Hespanhol VP. Lung cancer during pregnancy: an unusual case. Rev Port Pneumol 2014;20(01):46-49

16 Jemal A, Bray F, Center MM, Ferlay J, Ward E, Forman D. Global cancer statistics. CA Cancer J Clin 2011;61(02):69-90

17 Pereg D, Koren G, Lishner M. Cancer in pregnancy: gaps, challenges and solutions. Cancer Treat Rev 2008;34(04):302-312

18 Azim HA Jr, Peccatori FA, Pavlidis N. Lung cancer in the pregnant woman: to treat or not to treat, that is the question. Lung Cancer 2010;67(03):251-256

19 Garrido M, Clavero J, Huete A, et al. Prolonged survival of a woman with lung cancer diagnosed and treated with chemotherapy during pregnancy. Review of cases reported. Lung Cancer 2008;60(02):285-290

20 Mackenzie AP, Levine G, Garry D, Figueroa R. Glioblastoma multiforme in pregnancy. J Matern Fetal Neonatal Med 2005; 17(01):81-83

21 Cohen-Gadol AA, Friedman JA, Friedman JD, Tubbs RS, Munis JR, Meyer FB. Neurosurgical management of intracranial lesions in the pregnant patient: a 36-year institutional experience and review of the literature. J Neurosurg 2009; 111(06):1150-1157 